\title{
AS PROFISSIONAIS DA EDUCAÇÃO E A EQÜIDADE DE GÊNERO NAS COMUNIDADES LOCAIS.
}

\author{
LAS MUJERES EN EL DESARROLLO LOCAL
}

\author{
Marilia Gomes de Carvalho ${ }^{1}$ \\ Nadia Covolan ${ }^{2}$
}

\begin{abstract}
RESUMO
Este artigo trata de um programa de extensão universitária (que teve também um interesse de pesquisa) e foi desenvolvido por pesquisadoras e pesquisadores do GeTec - Grupo de Estudos e Pesquisas sobre Relações de Gênero e Tecnologia, da Universidade Tecnológica Federal do ParanáBrasil e o REGEDI - Grupo de Estudos sobre as Relações de Gênero e Diversidade da Universidade Federal do Paraná -campus Litoral - Brasil. Traz os resultados deste projeto, cujo objetivo foi sensibilizar as/os profissionais da educação sobre a eqüidade de gênero, a diversidade sexual e a homofobia em uma pequena comunidade do litoral do Paraná (Matinhos). As atividades foram estruturadas pelos seguintes temas: os conceitos de gênero e sexualidade; gênero e diversidade sexual no ambiente escolar, gênero, diversidade sexual, ciência e tecnologia e; gênero, diversidade sexual e mídia. As participantes do curso ministrado foram majoritariamente mulheres que trabalham em escolas deste pequeno município. As atividades foram pautadas pelo método participativo de maneira tal que as/os pesquisadoras/es trocavam conhecimentos sobre os temas planejados para o curso, com as participantes, para que estas últimas se transformassem em multiplicadoras das concepções de gênero mais igualitárias em suas comunidades locais. O método participativo permitiu a produção conjunta de conhecimentos sobre os problemas que as profissionais da educação encontram em sua prática escolar, como conseqüência de preconceitos e discriminações de gênero. Os resultados revelaram que: 1- as mulheres desta comunidade local reproduziam padrões de gênero dicotômicos e conservadores; 2- nunca haviam tido nenhuma informação sobre a construção social de gênero, nem sobre as desigualdades que são construídas entre homens e mulheres no âmbito do trabalho, mídia, ciência e tecnologia; 3. as mulheres participantes representam um importante instrumento de desenvolvimento local e de transformação das relações de gênero através de sua atuação na família e na escola.
\end{abstract}

Palavras-chave: Profissionais da Educação; Gênero; Diversidade Sexual; Formação de Professores.

\section{RESUMEN}

Este artículo es acerca de un programa de extensión universitaria, que tuvo también el interese de

1 Doutora em Antropologia Social; Professora do Programa de Pós-Graduação em Tecnologia PPGTE da Universidade Tecnológica Federal do Paraná - UTFPR; Coordenadora do Grupo de Estudos e pesquisas sobre relações de Gênero e Tecnologia - GeTec. E-mail: mariliagdecarvalho@gmail.com.

2 Doutora em Ciências Humanas; Professora da Universidade Federal do Paraná - UFPR; Coordenadora do Grupo Interdisciplinar de Estudos, Ensino-Pesquisa e Extensão em Representações de Gênero e Diversidade - REGEDI. E-mail:nira1@terra.com.br. 
investigación, y que fue desarrollado por investigadoras del GeTec - Grupo de Investigaciones acerca de las Relaciones de Género y Tecnología - de la Universidad Tecnológica Federal del Paraná-Brasil y el REGEDI - Grupo de Estudios acerca de las Relaciones de Género y Diversidad de la Universidad Federal del Paraná -campus Litoral-Brasil. Se trae los resultados de esto programa cuyo objetivo fue sensibilizar las y los profesionales de la educación sobre la equidad de género, la diversidad sexual y la homofobia en una pequeña comunidad del litoral del Paraná. Las actividades fueran estructuradas por los siguientes temas: los conceptos de género y sexualidad; género, diversidad sexual en el ambiente escolar; género, diversidad sexual, ciencia y tecnología; y género, diversidad sexual y medios de comunicación. Las participantes fueran mayoritariamente mujeres que trabajan en escuelas de la comunidad. Las actividades se pautaran por el método participativo de manera tal que las investigadoras cambiaban conocimientos acerca de los temas planeados con las participantes, para que se transformaran en multiplicadoras de concepciones de género más igualitarias en sus comunidades locales. El método participativo permitió la producción conjunta de conocimientos sobre los problemas que las profesionales de la educación encuentran en su práctica como consecuencia de prejuicios y discriminaciones de género. Los resultados revelarán que: 1- las mujeres de esta comunidad local reproducían padrones de género dicotómicos y conservadores; 2nunca habían tenido ninguna información acerca la construcción social de género y tampoco acerca de las desigualdades que son construidas entre hombres y mujeres en el ámbito del trabajo, medio de comunicación, ciencia y tecnología; 3 . las mujeres participantes representan un importante instrumento de desarrollo local y de transformación de las relaciones de género a través de su actuación en la escuela y en la familia.

Palabras clave: Profesionales relacionados a la Educación; Género; Diversidad sexual; Formación de Profesores.

\section{INTRODUÇÃO}

Além da família, instituição responsável pela educação e cuidados com os novos membros da sociedade, a escola é a outra instituição que também se ocupa desta tarefa, portanto família e escola são as principais responsáveis pelas masculinidades e feminilidades que estão sendo formadas em nossa sociedade. É no processo educativo, principalmente na família e na escola, que os padrões de comportamento, as regras sociais, os valores éticos e morais, os costumes, estereótipos, são transmitidos para as crianças (CARVALHO, 1992). A transmissão da cultura ocorre também através de outros mecanismos sociais, como a mídia ou a religião, mas família e escola são instituições fundamentais no processo de socialização dos novos membros da sociedade.

Tais instituições são justamente aquelas onde mais se observa a relevante posição ocupada pelas mulheres. Não se pode negar o importante papel que as mulheres têm na transmissão dos padrões de sociabilidade às novas gerações, não só em função da maternidade e o conseqüente cuidado com os filhos, que lhes é tradicionalmente delegado pela família, mas também porque na escola fundamental, especialmente nas séries iniciais, as mulheres ocupam quase que totalmente as funções de professoras, merendeiras, zeladoras, secretárias, diretoras, enfim são elas que estão à frente de todas as atividades escolares dirigidas para as crianças. As mulheres têm, pois um papel fundamental no desenvolvimento local e uma significativa tarefa na transformação (ou não) de suas comunidades em direção a padrões mais democráticos onde os direitos humanos sejam realmente respeitados.

Faz parte destes padrões culturais as concepções de gênero que incluem desde os papéis que devem ser desempenhados por homens e mulheres, até a rigidez de 
estereótipos de gênero que resultam quase sempre em preconceitos e discriminações. $\mathrm{O}$ movimento feminista vem há décadas questionando o lugar da mulher na sociedade e as relações de poder que permeiam a construção do gênero nas sociedades de tradição patriarcal. Porém não se pode negar que há mulheres que inadvertidamente têm reproduzido estes padrões, pois na medida em que são figuras principais na socialização das crianças, algumas vezes elas contribuem para a formação de homens e mulheres machistas e dominadores, que aprendem a adotar atitudes preconceituosas com relação à diversidade sexual. É claro que as mulheres não são as únicas responsáveis pela existência dos padrões sócio-culturais que existem há séculos e que foram por elas introjetados, porém não se pode negar a possibilidade de transformá-los através da atuação educativa das mães e professoras.

Foi a partir da constatação deste papel das mulheres em suas comunidades locais que foi elaborado o projeto intitulado "Refletindo Gênero na Escola: a importância de repensar conceitos e preconceitos" sobre o qual trata esta comunicação.

\section{O PROJETO}

O projeto referido acima visou contribuir para a formação de profissionais de ensino fundamental da rede pública municipal com relação aos seguintes itens:

- oportunizar o acesso a um referencial teórico que faça a discussão de conceitos como igualdade de gênero, homofobia, diversidade sexual

- provocar reflexões críticas entre os profissionais da educação sobre a construção dicotômica de gênero em nossa sociedade e suas conseqüências quanto à discriminação e preconceitos;

- sensibilizar profissionais da educação das escolas alvo do projeto para a modificação de estereótipos de gênero que geram comportamentos discriminatórios;

- auxiliar os/as professores/as a utilizar criticamente o material didático em sala de aula quanto aos conteúdos de gênero que contribuem para: (a) invisibilidade histórica das mulheres na construção da sociedade brasileira, da ciência e da tecnologia, (b) reprodução dos padrões tradicionais, conservadores e discriminatórios de gênero, tais como linguagem escrita e visual;

- problematizar questões como a violência de gênero, enfatizando a violência contra as mulheres, violência doméstica e violência contra homossexuais.

- problematizar juntamente com profissionais da educação, a definição de profissões "masculinas" ou "femininas" e o conseqüente direcionamento de e/ou enquadramento dos alunos em determinadas profissões (geralmente de conteúdos técnicos) e das alunas em profissões de conteúdos voltados às ciências humanas, às artes e às áreas do "cuidado";

- problematizar, juntamente com os profissionais da educação, comportamentos homofóbicos na sociedade em geral e na escola em particular e suas consequências de exclusão às pessoas que não seguem os padrões hegemônicos de gênero;

- repensar, junto aos profissionais da educação, formas de inclusão para todos que sofrem discriminação de gênero, seja por orientação sexual, seja por escolhas profissionais; 
A população para a qual se dirigiram os objetivos deste projeto foram os profissionais da educação da rede municipal de Matinhos, incluindo:

- Diretores/as das escolas, supervisores/as de ensino, professoras e professores, orientador/as educacionais, psicólogas/os, inspetoras/es, zeladores/as, serventes e demais profissionais.

- Pais da comunidade que têm participação ativa no cotidiano escolar como membros da associação de pais e mestres.

Este projeto foi desenvolvido pelo GeTec - Grupo de Estudos e Pesquisas sobre Relações de Gênero e Tecnologia do Programa de Pós-Graduação em Tecnologia da Universidade Tecnológica Federal do Paraná, Brasil, em parceria com o REGEDI Grupo Interdisciplinar de Estudos, Ensino-Pesquisa e Extensão em Representações de Gênero e Diversidade, da Universidade Federal do Paraná - campus Litoral e a Secretaria Municipal de Educação e Cultura de Matinhos, Paraná, cidade com um dos índices de desenvolvimento mais baixos do Estado do Paraná.

Os/as professores/as pesquisadores/as de ambos os Grupos de Pesquisa das duas universidades envolvidas ministraram as aulas seguindo a metodologia pedagógica participativa proposta pelo educador Paulo Freire, onde os conteúdos eram trazidos pelas profissionais da educação que fizeram o curso a partir de sua realidade vivida, seja na escola, com os/as alunos/as, seja em outras situações da vida. (FREIRE, 1970)

O curso foi planejado em quatro módulos que totalizaram 40 horas/aula, de acordo com a seguinte estrutura e conteúdo:

Módulo 1 - (8 horas/aula)

- Conceito de gênero

- Breve trajetória histórica

- Diversas abordagens

- Construção de feminilidades e masculinidades

- Conceito de sexualidade

- Problematização da heterossexualidade normativa

- Diversidade sexual (LGBTT)

- Gênero, diversidade sexual e saúde

- Violência de gênero e diversidade sexual

Módulo 2 - (16 horas/aula)

- Gênero e diversidade sexual no Ambiente Escolar

- Gênero e diversidade sexual nos livros didáticos

- Gênero e diversidade sexual no espaço escolar

- Gênero e diversidade sexual nos intervalos

- Gênero e diversidade sexual nas datas comemorativas

- Gênero e diversidade sexual no currículo explícito e oculto

Módulo 3 - (8 horas/aula)

- Gênero, diversidade sexual, ciência e tecnologia.

- Escolha da profissão

- Identificação com as disciplinas escolares 
- Gênero e diversidade sexual no acesso, produção e uso de tecnologias

Módulo 4 - (8 horas/aula)

- Gênero, diversidade sexual e mídia

- Representações de gênero e diversidade sexual nas diferentes mídias: TV, cinema, imprensa escrita, músicas, internet, teatro, publicidade, dentre outros, através de uma perspectiva crítica quanto a estereótipos preconceituosos e discriminatórios.

As professoras e professores desempenharam o papel de mediadoras/es, explorando a experiência vivida pelos profissionais da educação, trabalhando os conteúdos programados a partir da realidade trazida pelos participantes.

As atividades foram diversificadas, partindo de diversas dinâmicas de grupo, tais como: levantamento de situações-problema, oficinas, aulas expositivas dialogadas, vivências, palestras com especialistas no tema, utilização de recursos audiovisuais, confecção de cartazes temáticos, projeção de filmes e vídeos para discussões posteriores, dentre outras.

Estas dinâmicas foram aplicadas durante as aulas de forma tal que as pessoas participantes sentiam-se à vontade para falar sobre vários assuntos. Desde suas limitações na compreensão do tema gênero; as dificuldades de lidar com seus alunos ou alunas questões relacionadas à sexualidade; situações vividas em que reproduziam inadvertidamente padrões dicotômicos de gênero, sem a devida crítica às relações de poder que se estabelecem entre homens e mulheres; o incentivo maior dado aos alunos para as disciplinas voltadas para as ciências exatas; como a Matemática, por exemplo, e, por outro lado, o incentivo maior dado às alunas para o bom comportamento ou atividades que as preparavam para as áreas do cuidado; as dificuldades que tinham e, mesmo a falta de conhecimento adequado, para lidar com situações onde surgiam preconceitos e discriminações com relação a questões relativas à homossexualidade que muitas vezes culminavam em homofobia.

No decorrer das aulas os conceitos e preconceitos de gênero foram aos poucos sendo desconstruídos e foram construídos em seu lugar, pensamentos mais igualitários com relação a papéis de homens e mulheres na sociedade, abrindo a possibilidade da troca dos padrões tradicionais de homens e mulheres e provocando questionamentos sobre profissões majoritariamente masculinas ou femininas que dificultam a inserção das mulheres nas primeiras e dos homens nas segundas.

\section{BASE CONCEITUAL DO PROJETO}

Conceitos teóricos foram fundamentais para dar sustentação às idéias que nortearam este projeto desde a sua concepção até o encerramento das atividades e a sua avaliação. Não vamos trazer aqui detalhes minuciosos das discussões teóricas que acompanharam todo o processo, porém convém ressaltar alguns conceitos.

Segundo SIMIÃ̃, a categoria gênero pode ser entendida "como uma linguagem, uma forma de comunicação e ordenação do mundo, que orienta a conduta das pessoas em suas relações específicas, e que é, muitas vezes, base para preconceitos, discriminação e exclusão social" (2005, p. 13). Por sua vez, IRIS YOUNG (2003) compreende gênero 
como uma forma particular de posicionamento social dos corpos vividos em relação uns aos outros, dentro de instituições e processos históricos específicos que tem efeitos materiais na ação e reprodução de relações de poder e privilégio entre si. Sob essa ótica, o que significa dizer que indivíduos são "generizados" é que todos nós nos encontramos passivamente agrupados de acordo com essas relações estruturais, de maneiras muito impessoais para fundar identidades.

Assim, faz-se necessário refletir sobre as relações de gênero e diversidade sexual nos múltiplos setores da sociedade. Ao analisar livros didáticos, percebe-se claramente a ocultação de uma orientação não heterossexual e uma segregação feminina nas mais diversas disciplinas. Tais fatos constituem bases para a construção das identidades e da formação dos modelos que serão seguidos pelas crianças.

CASAGRANDE, (2005), aponta como os livros didáticos de matemática reproduzem representações de gênero estereotipadas e conservadoras que discriminam as mulheres de atividades da esfera pública, como o mundo do trabalho, ciência e tecnologia.

LOURO (1997) ressalta o papel da escola na construção e manutenção das diferenças entre homens e mulheres e aponta para a necessidade de demonstrar que "não são propriamente as características sexuais, mas é a forma como essas características são representadas ou valorizadas, aquilo que se diz ou se pensa sobre elas que vai constituir, efetivamente, o que é feminino ou masculino em uma dada sociedade em um dado momento histórico" (LOURO, 1997, p. 21).

Outra autora a ser considerada é WITTIG (1992), para quem o pensamento "hetero" apenas pode conceber uma cultura, ou sociedade, onde a heterossexualidade ordene as relações humanas, a produção de conceitos e os processos conscientes e inconscientes. Assim, é produzida uma leitura da realidade na qual os seres humanos são dados como não tocados pela história. A autora critica a psicanálise e o estruturalismo, referindo que foram encontradas no inconsciente as estruturas que tinham sido lá postas previamente; essas estruturas seriam opressoras porque, dizendo respeito a categorias como mulher, homem, sexo, relacionamentos, estão fundadas sobre a heterossexualidade, pensamento que produz a diferença entre os sexos como um dogma político e filosófíco. Assim, a diferença entre os sexos afeta todos os conceitos que integram as disciplinas, porém, não existe um ser-mulher ou um ser-homem porque não há nada de ontológico na diferença. A função da diferença é a de ocultar conflitos de interesse e a dominação heterossexual e masculina enquanto tal.

BOURDIEU (1999) lembra que as instituições estão há milênios inscritas na objetividade das estruturas sociais e na subjetividade das estruturas cognitivas, e pensam o feminino e o masculino com um espírito estruturado segundo esta oposição.

Para WITTIG (1981), a prática repetida de nomear a diferença sexual criou a divisão natural e somos obrigados em nossos corpos e mentes, a corresponder à idéia de natureza que foi estabelecida para nós. Assim, homens e mulheres são categorias políticas e não dados naturais.

BUTLER (2003) ilumina esse debate, referindo que o sexo não é o que alguém tem ou é, mas constitui uma das normas que qualifica um corpo para a vida no interior da inteligibilidade cultural. O que ocorre, é que os gêneros considerados inteligíveis, são aqueles que instituem relações de coerência entre o sexo, o gênero, a prática sexual e o desejo, dentro da norma heterossexual, requerendo e instituindo oposições assimétricas entre o feminino e o masculino. A matriz cultural na qual a identidade de gênero se torna 
inteligível exige que outros tipos de identidade não possam existir, ou seja, aquelas em que o gênero não decorra do sexo, ou onde as práticas do desejo não sejam coerentes com o que se espera de um sexo vinculado a um gênero, tais como mulheres que desejam afetiva e sexualmente outras mulheres e homens que se sentem atraídos afetivamente e sexualmente por outros homens.

Dessa forma, embora muito se tenha discutido, em anos recentes, sobre a imbricação da natureza/cultura, a heterossexualidade, orientação sexual da grande maioria das pessoas nas sociedades conhecidas, foi erigida em conhecimento tácito, axioma, princípio óbvio, dado pré-adquirido a qualquer ciência. No entanto, a heterossexualidade deve ser examinada enquanto categoria cultural, no sentido de que organiza a sociedade de forma hierárquica e assimetricamente generizada.

Essas questões são contempladas por Íris YOUNG (2003), quando propõe três eixos básicos de estruturas de gênero: a divisão sexual do trabalho, a heterossexualidade normativa e as hierarquias generizadas de poder. A estruturação de gênero na sociedade conforme a heterossexualidade normativa consiste nos diversos fatos ideológicos e institucionais que privilegiam a heterossexualidade, incluindo leis, regras políticas, organizações públicas e privadas; a educação formal e da mídia de massas seguem essas normas e supõem o que as pessoas fazem em suas relações com os outros. Esses fatos sociais constroem estruturas com diversas conseqüências na vida de diferentes homens e mulheres, que, com a variedade de inclinações sexuais, produzem grandes sofrimentos e limitações à liberdade. Assim, enquanto alguns procuram ajustar suas vidas, visando aceitação, outros vivem nas lacunas das relações sociais, e outros ainda, se rebelam contra essa normatização.

Como diz BOBBIO (2002), os preconceitos nascem nas cabeças das pessoas e devem ser combatidos, com o desenvolvimento das consciências, com a educação, e mediante a luta constante contra toda forma de discriminação. Para o autor, o juízo negativo que é dado em nossa sociedade às mulheres e à homossexualidade, também é de origem histórica e varia conforme as sociedades e no tempo. Estudos apontam que essa discriminação/preconceito está presente no ambiente escolar. Profissionais da educação, por exemplo, têm expectativas diferentes para meninos e meninas com relação à produtividade, ao capricho e às aptidões (CARVALHO, 2001). TABAK (2002) aponta ainda a permanência de carreiras e profissões tidas como "naturalmente" femininas e masculinas.

É relevante, portanto, que as/os profissionais da educação estejam atentas/os para que suas atitudes dentro e fora de sala de aula não reforcem a idéia de que as meninas e os meninos podem seguir apenas determinadas carreiras e que sua orientação sexual seja motivo para exclusão social ou a prática de violência contra pessoas que não se pautam pela heteronormatividade Os estudos acima apontam que as questões de gênero vêm sendo discutidas sob os mais diversos aspectos na Academia, porém essas discussões não atingem a população como um todo nem tampouco o ambiente escolar. Este fato ficou demonstrado na medida em que se avançava nas atividades junto às profissionais da educação do município de Matinhos e nas avaliações que elas mesmas fizeram do curso. 


\section{RESULTADOS DO PROJETO}

Pode-se dizer que os resultados do projeto foram positivos, pois tudo indica que houve um repensar entre as mulheres que fizeram o curso com relação à construção do gênero e uma re-avaliação da heterossexualidade normativa.

Reproduzimos aqui algumas frases das próprias mulheres sobre suas opiniões a respeito do curso, a fim de ilustrar as repercussões que as aulas tiveram em suas vidas. Foi dada a seguinte frase para que as alunas a complementassem: “Que bom que..."

"a questão da diversidade ficou mais clara, às vezes você não repara nos casos do gênero abordados; uma, porque são tão sutis e outra, porque já se está acostumado(a) com a situação”.

"pude ter a oportunidade de estar assistindo este curso, podendo ampliar minha visão em relação a gênero e diversidade, sabendo que não se trata apenas de uma questão de sexualidade em si, mas também de construção de conceitos sociais".

"eu pude participar desses temas tão importantes, para saber como tratar de vários temas diversificados". conceitos..."

"tive essa oportunidade de aprender tantas coisas novas e rever meus

"tive a oportunidade de participar deste curso... Adorei; gostei muito".

"tivemos a oportunidade de tratar de assuntos relacionados aos nossos materiais de trabalho como os livros"

"a nossa mentalidade se abriu mais"

"pude esclarecer algumas dúvidas e saber mais a respeito dos assuntos abordados"

"pudemos estar juntos, trocar experiências, aprendermos mais quanto aos aspectos cientificos, e curiosidades"

“abriu meu horizonte sobre sexo na escola, que é pouco falado até agora”.

"não perdi esta oportunidade de ampliar os conhecimentos sobre todos os assuntos debatidos neste curso”.

"está existindo a possibilidade de vivenciar, aprender, trocar experiências nesse curso de capacitação”.

"tive esse curso para nos ajudar a quebrar os tabus e enfrentar questionamentos futuros de nossos alunos com mais clareza”. 
os outros".

"tivemos esse curso para repensarmos nossas concepções e atitudes para com

"nós temos a capacidade de aprender a cada dia as coisas que nos são passadas, ensinadas, compartilhando com as outras pessoas, assimilando as palavras”.

As frases explicitadas pelas mulheres que freqüentaram o curso e reproduzidas aqui, demonstram que para algumas a expressão de "abrir a cabeça" foi recorrente. Para outras, houve referência à existência de preconceitos e tabus que o curso ajudou a desconstruir. Outras ainda referiram-se à idéia da ampliação de conhecimentos e a capacidade que tiveram para aprender coisas novas. Enfim, em uma comunidade pequena (cerca de 50 mil habitantes), onde a população vive relativamente isolada de grandes centros urbanos, (muitas mulheres vieram de escolas localizadas em áreas rurais) uma experiência como esta foi marcante.

Não se pode esquecer que elas todas são profissionais da educação e vão ser multiplicadoras das informações e conhecimentos que adquiriram. Exercem influência em suas famílias, nas escolas e na comunidade em geral. De acordo com Paulo Freire é através da educação que se consegue modificar a sociedade e esta experiência com as mulheres de Matinhos possibilitou-lhes a oportunidade de conhecer as questões de gênero, diversidade sexual, ciência e tecnologia a fim de levarem às suas comunidades o desenvolvimento necessário para construírem um mundo mais justo e igualitário.

\section{CONSIDERAÇÕES FINAIS}

Tendo em vista a importância do papel das mulheres no desenvolvimento local e sua efetiva influência nas comunidades onde vivem, através, principalmente, de sua atuação na família e na escola, é impossível não concluir com um clamor para a necessidade de uma ampliação da experiência aqui relatada e sua replicação em outras comunidades. Desta forma, será possível alcançar uma transformação mais abrangente e multiplicadora nas desigualdades de gênero e nas relações de poder entre homens e mulheres, tão comuns em sociedades de tradição patriarcal.

\section{REFERÊNCIAS}

BOBBIO, Norberto. A natureza do preconceito. Elogio da serenidade e outros escritos morais. São Paulo: UNESP, 2002.

BOURDIEU, Pierre. A dominação masculina. Rio de janeiro: Bertrand Brasil, 1999.

BUTLER, Judith. Problemas de gênero. feminismo e subversão da identidade. Rio de Janeiro: Civilização Brasileira, 2003.

CARVAlHO, Marilia Gomes de As Vicissitudes da Família na Sociedade Moderna. Tese de Doutorado em Antropologia Social. USP, 1992.

CARVAlHO, Marilia Pinto de. Mau aluno, boa aluna? Como as professoras avaliam meninos e meninas. Revista de Estudos Feministas, ano 9, $2^{\circ}$ semestre, 2001, p. 554-574

CASAGRANDE, Lindamir Salete. Quem mora no livro didático?.representações de gênero nos livros de matemática na virada no milênio. Dissertação de mestrado. Programa de Pós-Graduação 
em Tecnologia. UTFPR. Curitiba. 2005.

FREIRE, Paulo Pedagogia do Oprimido. Rio de Janeiro. Paz e Terra, 1987. (17 . Edição).

LOURO, Guacira Lopes. Gênero, Sexualidade e Educação: Uma perspectiva pós-estruturalista. Petrópolis, RJ: Vozes, 1997.

SIMIÃO, Daniel Schroeter. Gênero no mundo do trabalho: variações sobre um tema. Cadernos de Gênero e Tecnologia. Vol. 5, ano 2, 2005, p. 9-20.

WITTIG, M. One is not Born a Woman. Feminist Issues, v.1, n.2, 1981.

WITTIG, Monique. The straight mind and other essay. Boston: Beacon, 1992

TABAK, Fanny. O Laboratório de Pandora: Estudos sobre a ciência no feminino. Rio de Janeiro: Garamond, 2002.

YOUNG, Corpo vivido vs. Gênero: Reflexões sobre a estrutura social e subjetividade. Labrys, estudos feministas, n.3, jan./jul. 2003. 